\title{
Performance of Metal Buried Bridges in Sand
}

\author{
Ahmed Fahmy ${ }^{1}$, M. Meckkey El Sharnouby ${ }^{2}$ \\ ${ }^{1} 30$ Forensic Engineering \\ Toronto, ON, Canada \\ afahmy@30fe.com \\ ${ }^{2}$ Atlantic Industries Limited \\ Ayr, ON, Canada \\ melsharn@alumni.uwo.ca
}

\section{Extended Abstract}

Recent years have witnessed a surge in the use of corrugated metal plates in many structural applications including bridges, culverts and tunnels. The increasing popularity of these steel units owes to their many practical advantages including the use of high quality-controlled materials as opposed to the more conventional techniques such as concrete in addition to the easy and quick installation process.

While many existing studies provide general design guidelines for embedded structures in different soil profiles (e.g. $1,2,3$ and 4), to date a number of factors affecting the performance of embedded structures have not been thoroughly investigated. Accordingly, numerical analysis is used herein to model buried bridges in sands in the effort of providing indepth understanding of these factors and to ultimately provide a refined design procedure.

A two-dimensional finite element model is used to simulate the construction procedure of buried bridges in a cohesion-less soil profile. A parametric study was performed to examine the effects of dimensional parameters on the behaviour of the structure and to evaluate the induced strains and stresses in the soil zone surrounding it. The studied parameters include the structure geometry, the plate cross section, the bedding/founding soil properties and the lateral and vertical extents of the placed engineered fill. The results of the analysis were then compared to the available design guidelines in the commonly used design codes and manuals in North America.

The results showed the significant effect the different combinations of vertical and horizontal dimensions of the engineered fill have on the extents of the highly stressed soil zone surrounding the culvert. Less significant effects were observed on the bridge cross-section at greater overburden stresses. While the presence of granular engineered fill enhanced the culvert performance from a serviceability point of view, it resulted in an expansion of the highly stressed soil zone surrounding the structure. The results of this study present a starting step towards a more rigorous design procedure for the outlined structure. The outcomes of this study clearly show the need to improve the available design guidelines to accurately depict the soil-structure interaction and to ultimately provide a more cost-effective design approach taking into account the bottom-up construction procedure.

\section{References}

[1] J. Duncan, Soil culvert interaction method for design of metal culverts, Transportation research record 678. Transportation research board, National research council. Washington, DC, USA, 1978.

[2] J. H. F Vallee, "Investigation of increased wall stiffness on load effect equations for soil metal structures," M.S. Theses, Applied Science. Dalhousie University, NS, Canada, 2015.

[3] J. Vallee, J. P. Newhook, W. Ford, "Construction and Monitoring of Soil-Steel Bridge with Deeper Corrugated Plates," Proceedings of 9th International Conference on Short and Medium Span Bridges. Calgary, Alberta, Canada, 2014.

[4] K. Williams, S. MacKinnon, and J. Newhook, "New and innovative developments for design and installation of deep corrugated flexible steels structures," The $2^{\text {nd }}$ European conference on buried flexible structures. Poznan, Poland, 2012. 